\title{
Sosyal Bilgiler Öğretmenlerinin Öğretim ve Uygulamalarında Teknolojinin Entegre Edilmesine Yönelik Algıları
}

DOI: 10.26466/opus.660674

\author{
Adem Sezer* - Yusuf İnel ${ }^{* *}$ - Ali Gökalp ${ }^{* * *}$ \\ *Prof. Dr., Uşak Üniversitesi \\ E-Posta: adem.sezer@usak.edu.tr \\ ORCID: $\quad \underline{0000-0002-6854-0252}$ \\ ** Doç. Dr., Uşak Üniversitesi \\ E-Posta: yusuf.inel@usak.edu.tr \\ ORCID: $\quad$ 0000-0003-0739-5730 \\ *** Dr. Öğrencisi, Uşak Üniversitesi \\ E-Posta: gokalpali_1984@hotmail.com \\ ORCID: 0000-0002-3301-8392
}

\begin{abstract}
Öz
$B u$ araştırmanın amacı, sosyal bilgiler öğretmenlerinin eğitime teknoloji entegrasyonu algılarını tespit etmektir. Araştırma nitel araştırma yöntemine uygun olarak fenomonolojik araştırma deseninde gerçekleştirilmişsir. Araştırmanın çalışma grubunu 2017 - 2018 eğitim öğretimi güz döneminde, Uşak ilinde yer alan Milli Eğitim Bakanlığg'na bağh 12 farklı ortaokulda görev yapan gönüllü 15 Sosyal Bilgiler öğretmeni oluşturmuştur. Araştırmada veri toplama araştırmacılar tarafindan hazırlanan sorular ile öğretmenlerle yüz yüze görüşülerek gerçekleştirilmiştir. Elde edilen veriler betimsel analize tabi tutularak çözümlenmiştir. Araştırma sonucunda, Görselleştirme, Hizmetiçi Eğitim, Ĕ̆itime Teknoloji Entegrasyonu, Okul İmkânları, Ulaşabilirlik, Bilgisayar Laboratuarlı Ders ve Mesleki Yeterlilik temalarına ulaşılmıştır. Araştırmaya katılan öğretmenlerin etkileşimli tahtaların eğitim ortamında kullanılmasıyla ilgili hizmetiçi eğitimlere katıldı̆̆̊ lakin bu eğitimin teknolojinin eğitim ortamına entegrasyonu açısından yetersiz olduğu görülmüş̧ür. Sosyal bilgiler öğretmenlerinin Maddux ve Johnson'ın (2006) materyal ve teknoloji kullanma sinıflamasina göre Tip I boyutunda olduğu görülmüştür. Ayrica sosyal bilgiler öğretmenlerinin teknoloji kullanma ve öğretim materyali tasarlaması açısından yaratıcı fikir ve becerilerinin yetersiz olduğu ve teknoloji entegrasyonunu sadece sınıf içi bir etkinlik olarak düşündükleri sonuçlarına ulaşılmıştır.
\end{abstract}

Anahtar Kelimeler: Sosyal bilgiler, Teknoloji entegrasyonu, Sosyal Bilgiler Öğretmeni, Algı 


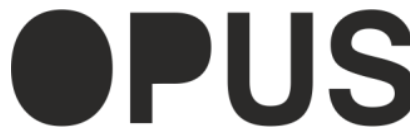

Uluslararası Toplum Araştırmaları Dergisi International Journal of Society Researches
E-ISSN : 2528-9535

YIl Year: 10

Cilt Volume: 16

Sayı Issue :Eğitim ve Toplum Özel Sayısı

Aralık December2020

Makalenin Geliş Tarihi Received Date: 17/12/2019

Makalenin Kabul Tarihi Accepted Date: 29/12/2020

\title{
Social Studies Teachers' Perceptions on Technology Integration in Education
}

\begin{abstract}
The aim of this research is to determine the perceptions of social studies teachers on technology integration in education. The research was carried out in the phenomenological research design in accordance with the qualitative research method. The study group consists of 15 volunteers who work in 12 different secondary schools in Uşak. Data collection was carried out by face to face interviews with teachers. The data were analyzed by qualitative descriptive analysis. As a result of the research, Visualization, In-service Training, Technology Integration to Education, School Facilities, Accessibility, Computer Laboratory Course and Vocational Qualification were reached. The teachers participated in the in-service trainings related to the use of interactive whiteboards in the educational environment, but this training was found to be insufficient in terms of integration of technology into the educational environment. Moreover, it was seen that social studies teachers were in Type I according to the classification of materials and technology by Maddux and Johnson (2006). Furthermore, it is seen that social studies teachers have insufficient creative ideas and skills in terms of designing and using technology. It was found that teachers think technology integration as only a class activity.
\end{abstract}

Keywords: Social studies, Technology integration, Social Studies Teacher, Perception 


\section{Giriş}

Günümüz dünyasında teknoloji hızlı bir şekilde ilerlemekte olup hayatımızın her alanına giren teknolojiden eğitim kurumları da yararlanmaya başlamıştır. Teknolojinin eğitim kurumlarına girmesi ise eğitim sürecinin gelişmesinde ve değişmesinde etkili olmuştur (Çoklar, Kılıçer ve Odabaşı, 2007). Bu gelişmeler ile birlikte eğitim ve teknoloji arasındaki ilişki, eğitim teknolojisi kavramın ortaya çıkarmıştır. "Eğitim teknolojisi; genelde eğitime, özelde öğrenme durumuna egemen olabilmek için bilgi ve becerilerin işe koşulmasıyla öğrenme ya da eğitim süreçlerinin işlevsel olarak yapısallaştırlması, öğrenmeöğretme süreçlerinin tasarlanması, uygulanması, değerlendirilmesi ve geliştirilmesi işidir" (Alkan, 1996, s.17). Çilenti (1988) ise öğrencileri eğitimin özel amaçlarına ulaştırma yollarını inceleyen bilim dalı şeklinde tanımlanmıştır (s. 30). Öğrenciler tek bir zekâ alanına sahip olmayıp birden fazla zeka alanına sahiptir (Gardner, 1993). Zekâ üzerindeki bu çalışma ile eğitimcilere öğrencilerin bireysel farklılıklarına değer veren programlar hazırlama olanağ 1 da sağlamıştır (Demircioğlu ve Güneysu, 2000). Eğitim alanındaki bu programlar ile teknoloji ilişkisi daha da güçlenmiş olup eğitim ortamında daha fazla duyu organını harekete geçirilmesi anlamlı ve kalıcı öğrenmelerin oluşmasına imkan tanımıştır (Çelik, 2007). Çilenti (1988) göre eğitim teknolojisinin ögelerinin hiyerarşik sıralaması somuttan soyuta doğru bir sıra izlemiş olup yaparak-yaşayarak öğrenme durumları da bu sıralamanın en üstündeki yerini almıştır.

Öğrenme ortamlarını zenginleştirebilmek, öğrencinin öğrenme sürecine dahil edilmesi adına eğitimde teknolojinin kullanımı ve teknolojiyi eğitim içinde entegre etme ile ilgili çalışmalar yapılmaya başlamıştır. Lakin teknolojiyi kullanma ve teknolojiyi entegre etme birbirlerinden farklı kavramlar olup teknolojinin derslerde kullanılıyor olması onun eğitimde entegre edildiği anlamını taşımamaktadır (Koehler ve Mishra, 2005). Powerpoint sunumları ve slayt gösterileri öğrenciyi sürece aktif edememesinden dolayı teknoloji kullanma kavramıla açıklanabilirken interaktif yazılım ve web siteleri gibi teknolojiler öğrencinin yaparak-yaşayarak öğrenmesine imkan tanıdığı için teknolojinin entegrasyonu kapsamında değerlendirilebilinir (Matheison, 2011). Holznogel (2005)'teki çalışmasına göre, teknoloji entegrasyonunun odağında müfredat ve öğretim olmalıdır şeklinde bir açıklama getirmesine rağmen başka bir araştırmada ise herhangi bir teknolojinin s1- 
nıflarda çok sık kullanılıyor olması veya öğretimin odağında teknolojinin kendisinin olması entegrasyonun tam olarak gerçekleştiği anlamına gelmemelidir şeklinde bir ifade kullanılmıştır (Stephens, 2011).

Öğrencinin ve öğretmenin teknoloji kullanması konusunda Tip I kullanı$m \imath$ ve Tip II kullanımı şeklinde iki farklı bakış açısı vardır. Tip I kullanımı geleneksel yollarla öğrenciye bilgi aktarım sürecini ifade ederken Tip II kulla$n ı m \imath$ ise öğrencinin aktif olduğu, teknoloji/materyalin öğrenci tarafından bizzat kullanıldığı ya da tasarlandığı süreci savunan görüştür (Maddux ve Johnson, 2006). Tip I ve Tip II kullanımlarını örneklendirecek olursak; herhangi bir sosyal bilgiler öğretmeninin Etkin Vatandaşlık öğrenme alanına ilişkin olarak 6.sınıf sosyal bilgiler dersi "Hâkimiyet Milletindir!" konusundan okullarda yapılan okul meclis seçim çalışmalarını ele aldığını düşünelim. Öğretmenin okul meclis seçimi çalışmalarının nasıl yapıldığını gösterir hazır slayt ya da dökümanları etkileşimli tahtaları kullanarak öğrencilere aktarması, teknolojiyi kullanma yani Tip I boyutunda olduğunu gösterir. Lakin öğretmenin akıllı tahta üzerinden Google Anket uygulamasını tanıtıp “Nasıl Bir Okul Meclis Başkanı Düşlersiniz?" konu başlı̆̆ı altında öğrencileriyle birlikte bir anket oluşturup, öğrencilerinden bu anketi kişisel bilgisayarları, laptop ya da akıllı telefonları ile sınıf içi ya da sınıf dışında doldurmalarını isteyebilir. Daha sonra öğrencilerin anketten elde edilen veriler ile başkan adaylarının özelliklerini karşılaştırıp okul meclis başkanlarını seçmeleri ve sürece aktif bir şekilde katılarak okul meclis başkanını nasıl belirleyeceklerini öğrenebilmesi ise teknolojinin entegrasyonu olan Tip II boyutuyla ilişkili olduğu söylenebilir.

Tip I ve Tip II bakış açısıyla değerlendirilen eğitime teknoloji entegrasyonu ile ilgili ülke içinde yapılan çalışmalar incelendiğinde; Şanlı, Sezer ve Pınar'ın (2016) çalışmalarında; coğrafya öğretmenlerinin, coğrafya öğretimde teknoloji entegrasyon algıları ve uygulamalarını ortaya koymak amaciyla nitel bir araştırmanın olduğu görülmektedir. Araştırmada görüşme yöntemi ile veriler toplanmış olup çalışma grubuna dahil olan öğretmenlerin teknoloji uygulamaların ise Maddux ve Johnson (2006) Tip I ve Tip II boyutlu yaklaşımından yararlanarak değerlendirmişlerdir. Çalışma grubundaki öğretmenlerin teknolojinin entegrasyonuna ilişkin bilgilerin yetersiz olduğu ve aynı zamanda katılımcıların çoğunun Tip I boyutunda olduğu sonucuna ulaşlmıştır. 
Teknolojinin entegrasyonu kapsamında diğer çalışmalara bakıldığında; Kefeli (2013), etkileşimli tahtanın öğrenme-öğretme sürecine entegrasyonuna ilişkin ilköğretim öğretmenlerine yönelik hizmetiçi programın geliştirilmesi, uygulanması ve kursun etkililiğini değerlendirerek öğretmenlerin eğitsel uygulamalara yönelik yansımalarını incelemek amacıyla bir çalışma yürütmüştür. Araştırma sonucunda, etkileşimli tahtanın öğrenme-öğretme sürecine entegrasyonunu sağlaması açısından hizmetiçi kurs programının katılımcların bilgi ve becerisini geliştirdiği lakin bu kursun etkili teknoloji entegrasyonu için yeterli olmadığını ve kurs sonrası destek eğitimlerin önemli olduğunu dile getirmiştir. Sarı ve Altun (2015) tarafından yürütülen başka bir çalışmada, sınıf öğretmenlerinin ilkokul matematik öğretiminde teknoloji kullanımına ilişkin algılarını belirlenmesi amaçlanmıştır. Sınıf öğretmenlerinin teknolojiyi kullanma konusunda zorluklar yaşadığını ifade etmişlerdir. Sınıf öğretmenlerinin matematik öğretiminde teknolojiyi soyut kavramların somutlaştırılması, kaynak kitapların projeksiyon aracılığı yansıtmak, ödev kontrolü sağlamak, internet ortamındaki video ve görselleri paylaşarak öğrenme ortamında değişiklik yapmak gibi amaçlar için kullandıklarını dile getirmişlerdir. Bu araştırmanın sonuçları ile Demir, Özmantar, Bingölbali ve Bozkurt (2011)'deki sınıf öğretmenlerinin teknoloji kullanmalarının irdelenmesine yönelik araştırmalarının sonuçlarıyla benzer özellik taşıdığı görülmüştür. Çakır ve Yıldırım (2009)'da bilgisayar öğretmenlerinin okullarda teknoloji entegrasyonu hakkındaki düşüncelerini belirlemek amacı taşıyan çalışmada; sınıfların kalabalık olması, sınırlı erişim ve öğretmenin yetersiz bilgisi gibi pek çok unsurun bilgisayar öğretmeni adaylarının ve öğretmenlerinin okullarda teknoloji entegrasyonunu etkilediği sonucuna ulaşılmıştır.

Teknolojinin entegrasyonu kapsamında yurtiçinde ulaşılan çalışmalar değerlendirildiğinde; teknolojinin entegrasyonuna yönelik hâkim iki bakış olan, Tip 1 ve Tip II boyutu açısından değerlendirmeleri içeren çalışmaların azlığ1 görülmüş̧ür. Bunun yanında teknolojinin entegrasyonuna yönelik ortaokul kademesi sosyal bilgiler dersi öğretmenleri ile yürütülen bir çalışmaya rastlanılmaması da dikkat çeken bir durumdur. Tüm bu tespitlerden hareketle, bu çalışma ile sosyal bilgiler öğretmenlerinin teknoloji entegrasyonu yönündeki algıları ve algılarına etki eden dinamiklerin ortaya çıkartılması amaçlanmıştır. Böylece bu araştırmanın ilgili literatüre katkı sağla- 
ması ve alanda çalışma yapacak araştırmacılara kaynak teşkil etmesi düşünülmektedir.

\section{Yöntem}

Araştırmada nitel çalışma türlerinden olgu bilimi (fenomoloji) kullanılmıştır. Olgu biliminde amaç, araştırma katılımcılarının bir olguya ilişkin deneyimlerinin neler olduğu tanımlanmaya çalışılır (Creswell, 2007). Çalışmada, sosyal bilgiler öğretmenlerinin öğretim ve uygulamalarında teknolojinin entegrasyonu algılarını yine kendilerinin deneyimleriyle ortaya çıartılması amaçlandığı için olgu bilimi tercih edilmiştir.

\section{Çalışma Grubu}

Araştırmanın çalışma grubunu Uşak ilinde yer alan Milli Eğitim Bakanlığı'na bağlı 12 farklı devlet ortaokulunda görev yapan ve gönüllü olan 15 sosyal bilgiler öğretmeni oluşturmaktadır. Bu 15 öğretmeninin 8'i kadın, 7'si erkektir. Kadın olanlar $K-1, K-2, K-3 \ldots$, erkekler öğretmenler ise $E-1, E-2, E-$ $3 . .$. şeklinde kodlanarak katılımcıların gizlilikleri sağlanmıştır. Çalışma grubunu oluşturanların kişisel bilgileri ise Tablo 1'de yüzdelik ve frekanslariyla birlikte sunulmuştur.

Tablo 1. Çalışma grubuna ait kişisel bilgiler

\begin{tabular}{|c|c|c|c|}
\hline Değişken & Kategori & Frekans & Yüzdelik \\
\hline \multirow{3}{*}{ Cinsiyet } & 1.Erkek & 7 & 47 \\
\hline & 2.Kadın & 8 & 53 \\
\hline & Toplam & 15 & 100 \\
\hline \multirow{6}{*}{ Kıdem Yilı } & $1.0-5 \mathrm{yll}$ & 5 & 33 \\
\hline & $2.6-10 y \mathrm{yl}$ & 2 & 15 \\
\hline & 3.11-15yl & 3 & 20 \\
\hline & $4.16-20 \mathrm{yll}$ & 4 & 25 \\
\hline & 5.21yıl ve üstü & 1 & 7 \\
\hline & Toplam & 15 & 100 \\
\hline \multirow{5}{*}{ Mezun Olunan Program } & 1.sosyal bilgiler & 11 & 71 \\
\hline & 2.tarih & 2 & 15 \\
\hline & 3.coğrafya & 1 & 7 \\
\hline & 4.sinıf öğretmenliği & 1 & 7 \\
\hline & Toplam & 15 & 100 \\
\hline \multirow{4}{*}{ Öğrenim Düzeyi } & 1.lisans & 13 & 85 \\
\hline & 2.yüksek lisans & 2 & 15 \\
\hline & 3.doktora & 0 & 0 \\
\hline & Toplam & 15 & 100 \\
\hline \multirow{4}{*}{ Görev Yapılan Okul Türü } & 1.köy okulu & 7 & 47 \\
\hline & 2.ilçe merkez okulu & 3 & 20 \\
\hline & 3.il merkez okulu & 5 & 33 \\
\hline & Toplam & 15 & 100 \\
\hline
\end{tabular}




\begin{tabular}{llll}
\hline Lisans Eğitiminde Teknoloji ve & 1.evet & 14 & 93 \\
Materyalleri Dersi Alma Durumu & 2.hayır & 1 & 7 \\
& Toplam & $\mathbf{1 5}$ & $\mathbf{1 0 0}$ \\
\hline & 1. üst & 5 & 33 \\
Görev Yapılan Okulun & 2. orta & 7 & 47 \\
Sosyoekonomik Düzeyi & 3.alt & 3 & 20 \\
& Toplam & $\mathbf{1 5}$ & $\mathbf{1 0 0}$ \\
\hline
\end{tabular}

\section{Verilerin Toplanmast}

Nitel araştırma türlerinden olgu bilimi deseniyle yapılandırılan bu araştırmada, verilerin toplanması adına görüşme yöntemi tercih edilmiştir. Nitel araştırmalarda görüşme, temel veri toplama araçlarındandır. İnsanların gerçekliğe ilişkin algılarına, anlamlarına, tanımlarına ve gerçeği inşa edişlerine göre vakıf olmanın bir yolu, aynı zamanda başkalarını anlamak için kullanılan en güçlü yöntemlerdendir (Punch, 2005, s.165). Bu tanımdan hareketle, araştırma verileri yarı yapılandırılmış görüşme soruları ile toplanmıştır. Yarı yapılandırılmış görüşme tekniği, araştırmacı tarafından hazırlanan sorular üzerinde yanıtlayıcının kısmen düzeltme, düzenleme hakkı vardır. Sorgulayan ve yantlayan, bazı soruları birlikte yeniden düzenleyebilirler. Ve bu teknik genellikle nitel araştırmalarda kullanılır (Sönmez ve Alacapınar, 2014, s.152). Çalışma verilerinin toplanması amacıyla yarı yapılandırılmış mülakat soruları hazırlanmış olup belirlenen zamanlarda katılımc1larla görüşmeler yapılmıştır. Görüşme öncesi katılımcıların rızası alınarak veriler akıllı telefon vasitasıyla depolanmıştır. Hemen ardından veriler yazılı ortamına aktarılarak analize hazır hale getirilmiştir.

\section{Verilerin Analizleri}

Araştırma verilerin çözümlenmesi için betimsel analiz tekniği kullanılmıştır. Betimsel analiz; verilerin olduğu gibi gösterildiği, betimlendiği, resmedildiği, anlatıldığı bir irdelemedir. Yani ayrıntılı ve kurmacaya dayalı bir araştırma söz konusu değildir. Araştırmacı sorduğu soruları bir kavram, bir cümle ile ifade edip bunlar katılımcıların cevaplarına uygun ve onları kapsayacak bir nitelikte olmalıdır (Sönmez ve Alacapınar, 2014, s.244). Yapılan açıklama doğrultusunda, katılımcıların verdikleri cevapları ifade edecek kodlamalar 3 ayrı kodlayıcı tarafından yapılmıştır. Daha sonra kodlardan temalara ulaşılmıştır. Tüm bu işlemler de tablolar halinde verilip bulgular örnek katılımcı yanıtlarıya desteklenerek yorumlanmıştır.

\section{Bulgu ve Yorumlar}


Araştırmaya katılan sosyal bilgiler öğretmenlerine, derslerde teknoloji kullanımı hakkında düşüncelerinin tespiti amaçlı birtakım sorular yöneltilmiştir. Bu işlemin sonucunda Tablo 2 ' de sunulan kodlar ve temaya ulaşılmıştır.

Tablo 2. Derslerde teknoloji kullanıma yönelik tema ve kodlar

\begin{tabular}{ll}
\hline Tema & Kodlar \\
\hline & Etkileşimli tahtalar, harita, küre ve akllı telefonlar, slaytlar ve maketler, \\
Görselleştirme & video, çizgi film ve filmler, EBA ve genel ağ arama motorları \\
\hline
\end{tabular}

\section{Görselleştirme}

Katılımcıların derslerde teknoloji kullanımına yönelik düşüncelerine açıklık getirebilmek adına, katılımcılara derslerde teknolojiyi nasıl kullandıklarını bahsetmeleri istenmiştir. Araştırmanın bu giriş sorusunun sonucunda Tablo 2'de belirtilen kodlar ve Görselleştirme teması elde edilmiştir.

- E-1:6.smnf üretim konusu ile ilgili tarm ürünleri hakkında çeorenizde yetişen tarm ürünleri hakkmda ödev, bu ödevin de slayt gösterisi şeklinde evlerinde hazırlayıp akıllı tahta aracilığıla sunum yapmalarmı istedim. İmkânı olmayan ögrencilere ise üretimle ilgili görseller oluşturup getirmelerini istedim.

- E-2: Derslerimde de teknoloji kullanıyorum. Özellikle akıll tahtayı kullaniyorum. Son günlerde işlediğim dersten bahsedecek olursak; demokrasinin tarihi gelişimini teknolojizi kullanarak yani akıll tahtayı kullanarak konumu işle$\operatorname{dim} \ldots$

- E-3: 5.sinıflarda en son kullandığımda, bölgemizde yetiştirilen ürünler ve bunlara bağgl olarak ekonomik faaliyetler, meslekler vs. akıllı tahta yardımıyla dersi görsel olarak işledik. Görsellerden yararlandık...

- K-1: Derslerde teknoloji kullanımın özellikle akıllı tahtaların çok faydalı olduğunu düşünüyorum. Özellikle görsellik açısından bizim derslerimizde haritalarn gösterirken ya da örnek verirken görsellik açısından faydal oluyor... Bir de kazanım testlerini ya da çıkmış sorularn akull tahta üzerinden yansitıyoruz.

- K-3: EBA üzerinden çizgi film olsun diğer etkinliklere tarih konularmı zevkle hale getirebiliyorum. Teknolojiden kasit okullarmmzda akıllı tahta EBA var. Teknolojiden kasıt bu herhalde yani.. Akill tahta üzerinden arama motorlarmı, kendi telefonumdan olsun flash disklerden yararlanarak oradaki görsel ve videoları ögrencilere sunuyorum.

- K-5:İstanbul'un Fethi'ni anlatım diyelim çocuklara... Maketini yapıyoruz, dokunmalarmı sağlıyoruz. Ve bununla ilgili film de izlettirebiliyoruz. 
- K-6:Görselleiğin önemli olduğunu düşünüyorum...5.sinıf meslekler konusunda akıll tahta üzerinden EBA'dan yararlandım...

- K-8:Öğrenciler görsel olarak izlediklerini daha çok akıllarında tutuyor.

Katılımcıların vermiş olduğu cevaplar incelendiğinde, katılımcılar teknoloji kullanımını, akıllı tahta ve akıllı tahta yardımıyla ulaştıkları eğitim programları ile ilgili ders konularını görselleştirme olarak algıladı̆̆ı görülmektedir. Başka bir ifadeyle, katılımcıların ilgili ders konularını görselleştirebilmek adına teknolojiyi kullandıkları söylenebilir.

Görselleştirme algısını temellendirebilmek adına, katılımcıların derslerde tercih ettikleri teknoloji ve öğretim materyallerinin neler olduğu ve teknoloji destekli dersleri tasarlarken neleri göz önünde bulundurduklarına yönelik yanıtları verilmiştir.

- E-1 Akull tahta, cep telefonu, küre, harita, model ve maketler...

- E-2:Akıllı tahta ve tahtaların içeresinde kullandığımız EBA, Okulistik, Morpa Kampus. Bunların dişında yok.

- E-3: Akıll tahta, harita, küre ve kendi cep telefonum... Öncelikle öğrenci seviyesine uygun mu, dersi keyifli hale getiriyor mu ona bakarm... Öğrenci merkezli eğitim olduğu için görsellerle ve kendi katıldığı zaman dersi unutmadığını gördük.

- E-4: Etkileşimli tahta, EBA, vitamin gibi portallardan yararlanıyorum.

- K-1: Küre, harita, atlas ve belgesel izlettireceksem akıllı tahtayı kullanıyorum. Derslerimi tasarlarken bütün öğrencilere hitap edebilmesi... Yani dikkat çekiciliği, dersin anlatımın kolaylaştırmasını...

- K-2:Harita, akıllı tahta...

- K-3: Haritalar, akull tahtalar, ders kitapları...

- K-4: Akıllı tahta ve buna bağh EBA ve diğer programlar. Haritaları kullanmıyoruz çünkü bunlar akıll tahta içerisinde var... Öğrenci seviyesine uygunluk, güncel olaylarla ilişkili ve görselliğine bakarm.

- K-5: Akıllı tahta, küre, harita ve cep telefonum. Dikkat çekici ve görüntü ve ses sistemine bakryorum.

- K-8: En fazla akıllı tahtayı kullanırm. Daha sonra flash disk ve bilgisayarmı kullanirım.

Verilen cevaplar incelendiğinde, katılımcıların en çok ve en sık tercih ettikleri teknoloji ve öğretim materyalinin akıllı tahtalar olduğu, yine katılımcıların vermiş olduğu cevaplar doğrultusunda, kullanılan öğretim materyallerin ve teknolojik destekli tasarlanan derslerin merkezinde öğretmenin 
olduğu ve sunum amaçlı kullanıldığ görülmektedir. Elde edilen bulgulardan hareketle, katılımcıların derslerinde teknoloji ve öğretim materyallerini tercih etme sebeplerinin ders konularını görselleştirebilmek gibi bir algıya sahip olduğu söylenebilir. Katılımcların görselleştirme algılarının ilişkili olduğu bir başka tema ise Tablo 3 'te verilmiştir.

Tablo 3. Eğitime teknoloji entegrasyonuna yönelik tema ve kodlar

\begin{tabular}{ll}
\hline Tema & Kodlar \\
\hline & Teknolojinin eğitimle kaynaştırlması \\
& Teknolojinin eğitimle birleştirilmesi \\
Eğitime Teknoloji Entegrasyonu & Teknolojinin eğitimle uyumu \\
& Teknolojinin eğitimde uygulanması \\
\hline
\end{tabular}

Tablo 3'te tek bir tema ve bu temanın ulaşılmasını sağlayan 4 farklı kodun olduğu görülmektedir. Eğitimde teknoloji entegrasyonu teması ile ilişkili katılımcılardan gelen bazı yanıtlar aşağıda verilmiştir.

\section{Eğitime Teknoloji Entegrasyonu}

- E-1:Eğitimle teknolojinin birleştirmesini anliyorum. Sosyal bilgiler dersi soyut kavramlar var. O yüzden öğrencinin dikkatini çekmesi açısından yararl olur. Çünkü oradaki görsellerle, videolarla dersi desteklemek öğrencinin öğrenmesini daha çok kolaylaştırır.

- E-2: Teknolojik aletlerle dersin uyumlu bir şekilde kullanıldığın anlyyorum. Sosyal bilgiler dersinde özellikle tarih konularında... Türk devletlerin yaşayışına ilişkin bir animasyon ya da bir çadırn görselinin göstermesi açısından... Çünkü bu görselleri akıllı tahta üzerinden gördüğ̈̈nde bunun daha kalıı ve anlaşılı olabileceğini düşünüyorum.

- E-3: Teknolojinin eğitime uyumu, bütünleşmesi, teknolojinin eğitimde kullanımı geliyor aklıma. Sosyal bilgilerde eğitimde teknolojinin entegrasyonu için yine akull tahtalarn kullanmaliyız... Akull tahtalar üzerinden yine görseller varsa desteklenir ve ünite sonundaki test soruları ekran üzerine yansitılip çocuklarm akıll tahtalarn kullanmalar istenebilir.

- K-4:Teknolojiyi simıf ortammda kullanabilmek... Örneğin 5.sinfflarda yer alan toplum için çalışanlarla ilgili konu bazında oluşturduğumuz slaytlarla bilgiyi sunmaya çalıştım.

- K-6: Eğitimde teknolojinin bütünleştirilmesi, derslerin teknoloji ile birlikte işlenmesi gibi bir şey anlyyorum. Sosyal bilgilerde uygulama örneği olarak sadece yükselti basamakların göstermek için harita boyaması yaptırdım. 
Katılımcıların yantları incelendiğinde, eğitime teknoloji entegrasyonuna yönelik düşüncelerinde tam bir netlik olmadığ görülmektedir. Bunun yanında sosyal bilgiler dersi açısından teknolojinin entegrasyonuna yönelik uygulama örneklerinin daha çok öğretmen merkezli bir yapıda olduğu ve yine bu uygulama örneklerinin daha çok görselleştirme boyutunda olduğu ifade edilebilir. Buradan edinilen bulguları araştırmanın Görselleştirme teması ile ilişkilendirdiğimizde, her iki temanın da merkezinde akıllı tahtaların olduğunu ve katılımcıların teknolojinin sadece görsellik boyutundan yararlandığını söylenebilir. Ayrıca bu iki temadan edinilen bulguların katılımcıların görselleştirme algısı ile ilişkili olduğunu söylemek isabetli olacaktır.

Görselleştirme algılarını derinleştirebilmek adına, katılımcıların sosyal bilgiler dersinde öğretim teknolojileri ve materyalleri kullanma amaçlarına yönelik bulgular Tablo 4 'te gösterilmiştir.

Tablo 4. Kullanım amaçlarna ulaşabilmeye yönelik tema ve kodlar

\begin{tabular}{ll}
\hline Tema & Kodlar \\
\hline Ulaşabilirlik & Yeterli, Kısmen \\
\hline
\end{tabular}

Katılımcların, sosyal bilgiler dersinde öğretim teknolojileri ve materyalleri kullanma amaçlarına yeterli ve kısmen şeklinde ulaştıkları bilgisi edinilmiştir. Edinilen bu veriler ışığında Ulaşabilirlik teması elde edilmiştir. Katılımcı cevaplarından bazıları aşağıda verilmiştir.

\section{Ulaşabilirlik}

- E-1:Metaryal sayısı simırl olduğu için bütün amaca hizmet etmiyor. Ama genel olarak amaçlarma hizmet ettiğini düşünüyorum ama tam anlamıla değil. Soyut kavramlar görsellerle desteklenmesi amactma hizmet etme konusunda yeterlidir.

- E-2: Evet kullanım amaçlarıma ulaşabiliyorum. Örneğin Türkiye'de iklim çeşitleri işlediğimde bu materyalleri görsel olarak kullanıyorum ve amactna da ulaştığııı düşünüyorum.

- E-4:Evet ulaşabiliyorum. Özellikle soyut temelli konularda bu teknolojik ürün ve materyaller dersimin somutlaştırmasını sağlıyor ve böylece amactma ulaşabiliyorum bu yönden.

- E-5: Evet ulaşabiliyorum. Aradığım görsel olsun ve diğer konulara ilişkin dökümanlar akill tahtalarımizda mevcuttur. 
- K-4: beni ulaştıriyor ben öyle düşünüyorum. Çünkü akıllı tahta ve slayt olmadığı zaman daha çok efor harcamıs olacaksınız. En azından akill tahta ve slaytlarla görselliğe girerek bilgilerin unutmamaların să̆lıyoruz. Bunu yaparken de soru ve cevaplarla öğrenciyi de sürece katmaya çaliyoruz.

- K-8: Derslerde konu tekrar yapmak için EBA programmdan video izlettirebiliyor, test çözdürebiliyoruz.

Katılımcıların cevapları incelendiğinde, öğretim teknoloji ve materyallerinin kullanma amaçlarının içeriğinin genel olarak soyut konuların görsellerle somutlaştırması, ders konularında görsellik yönünden zengin içerik sağlaması ve konu tekrarlarının yapılması şeklinde olduğu görülmektedir. Ulaşabilirlik temasından elde edilen bulguların da katılımcıların görselleştirme algısı ile ilişkili olduğu söylenebilir.

Katılımcıların görselleştirme algısı altında yatan dinamiklerin neler olduğunu görebilmek adına ise katılımcıların hizmetiçi öğretim teknolojileri ve materyalleri konulu program hakkındaki düşüncülerine başvurulmuştur. Buradan edinilen bulgular da Tablo 5'te verilmiştir.

Tablo 5. Hizmetiçi eğitimin içeriğine yönelik tema ve kodlar

\begin{tabular}{ll}
\hline Tema & Kodlar \\
\hline \multirow{3}{*}{ Hizmetiçi eğitim } & Akıllı tahta (etkileşimli tahta) kullanımı \\
& Materyal geliştirme ve kullanma \\
& Ĕ̈itim içerikli program ve yazıllımlar \\
\hline
\end{tabular}

Tablo 5'te üç farklı kodun oluşturduğu tek bir temanın olduğu görülmektedir. Bu temayla ilişkili katılımcıların vermiş olduğu cevaplardan bir kısmı aşağıda sunulmuştur.

\section{Hizmetiçi eğitim}

- E-1:Evet katıldim. Akıll tahta ve bu tahtaya bağh olarak EBA kullanmmina yönelik bir hizmetiçi eğimine katıldım.

- E-2: Katıldım. Bu eğitimde bize akıllı tahta kullanımı üzerinde eğitim verildi. Bunun dışında almadık.

- K-7: Akıllı tahta kullanımına yönelik uzaktan eğitim aldık.

Yanıtları verilen katılımcıların dışında, E-3, E-4, K-1, K-2, K-6 kodlu katılımcıların da akıllı tahtaların kullanımına yönelik hizmetiçi eğitim aldıkları lakin diğerlerinin böyle bir eğitim programına katılmadıkları bilgisi edinil- 
miştir. Hizmetiçi eğitim teması ile görselleştirme algısını ilişkilendirebilmek adına aşağıdaki yanıtlara gereksinim duyulmuştur.

- E-1:Materyal kullanımı dışında geliştirme içerikli bir eğitim verilirse iyi olacağını düşünüyorum.

- E-2: Soyut kavramlarm öğretilmesine yönelik materyallerin üretilmesine yönelik....kendi branşımda örnek materyal tasarlamış arkadaşların sunum, hizmetiçi eğitim verebilmelerini isterdim.

- E-3: İçerikleri kendim hazırlayabilme yeteneğim olursa daha iyi olur. Biz hazırcılık yapıyoruz. Ben isterdim ki ben bir şeyler hazırlayabileyim. Profesyonel kişiler tarafindan bazı programların yazılımların nasıl yapılacă̆ına dair eŏitimlerin verilmesini isterdim ve bu da çok hoş olurdu.

- K-5:Basit malzemelerden çok kaliteli bir ürün tasarlayabileceğimiz bir e ğitim verilmesini isterdim.

- K-6: Becerimin geliştirmesini isterdim. Materyalin bana nasıl yapılacă̆ını öğretmeli mesela bir kabartma haritasını yapmayı öğretmeli vb.

Edinilen cevaplar doğrultusunda, katılımcıların öğretim teknolojileri ve materyal geliştirme konusunda becerilerinin eksik olduğu görülmektedir. Başka bir ifade ile açıklamak gerekirse, araştırmaya katılanların öğretim teknoloji ve materyalleri konusunda yaratıcılıklarını yetersiz düzeyde gördükleri söylenebilir. Bunun yanında, Tablo 1'de, 15 katılımcının 14'ü hizmet öncesi öğretim teknolojileri ve materyal geliştirme ile ilgili lisans düzeyinde eğitim aldıkları bilgisine ulaşılmıştır. Bu bulgunun, katılımcıların lisans döneminde materyal tasarlama hususundaki bilgilerinin yetersiz olduğu ya da lisans döneminde edindikleri bilgilerin kalıcılığının olmadığı şeklinde yorumlanabilir. Hizmetiçi eğitim temasından edinilen tüm bulgulardan hareketle, öğretim teknolojileri ve materyalleri konusunda katılımcılara sunulan hizmetin yetersiz olması, katılımcıların öğretim teknoloji ve materyal konusundaki bilgi ve becerilerinin yetersiz olması, katılımcıların görselleştirme algısına sahip olmasında etkili olduğu ifade edilebilir.

Katılımcılara, sosyal bilgiler dersini bilgisayar laboratuvarında işleme ile ilgili sorular yöneltilip bu ortamda ders işleme sürecinin ana hatlarıyla anlatmaları istenmiştir. Katılımcıların verdiği cevaplar doğrultusunda, okulların büyük bir bölümünde bilgisayar laboratuvarı olmadığı ya da olan okullardaki bilgisayarların kullanım dışı olduğu bilgisini vermişlerdir. Bu bilgi edinildikten sonra bilgisayar laboratuvarında ders işleme imkânı verildiği 
takdirde derslerini nasıl işleyecekleri sorulmuştur. Bu soru karşısında Tablo 6 'da sunulan tema ve kodlar elde edilmiştir.

Tablo 6. Bilgisayar laboratuvarlarna yönelik tema ve kodlar

\begin{tabular}{ll}
\hline Tema & Kodlar \\
\hline Bilgisayar Laboratuvarlı Ders & Sunum, Görsel, Yetersizilik \\
\hline
\end{tabular}

Tablo 6 incelendiğinde, bir tema ve bu temanın oluşumunu sağlayan 3 ayrı kodun olduğunu görülmektedir. Bilgisayarla Laboratuvarlı Ders temasına ilişkin katılımcılardan bazılarının cevapları aşağıda verilmiştir.

\section{Bilgisayar Laboratuvarh Ders}

- E-1:Bu sinıflar kaldırıldığı için işleme şansım yok. Sosyal bilgiler dersi açısından öğrenciyi dersin içine katarak bu bilgisayar ortamında öğrencinin kendi sunumunu kendi hazırlayıp sunmasını sağlardım.

- K-1: Hayır direk yok çünkü bilgisayarlarımız çok eski. Çok başarılı olamayabilirim aslında. Çünkü bilgisayar... Ve çocuğa kullandırma aşamasında zorluk çekebilirim. Bilişim öğretmeni de yok. Hem öğrencilerim hem de ben yetersizim. Süremiz de kısıtlı olduğu için faydalanamam.

- K-3:Bilgisayarlarımız eski ve şuan kullamlmıyor. 8.sinıflarda 2 ders saatim var. Ben çocuğa konumu anlatayım, testi mi çözdüreyim, laboratuvara mi götüreyim... Ve bunun yanında öğrenciye sunabileceğim güzel şeylerin hazırlanması da lazım. Video ve bu tür şeyler de akull tahtalardan görüyorum bilgisayar lab. gerek yok.

- K-4:Bilişim lab. Okulumuzda yok. Olsaydı günün konusunu ekran üzerinden görmesini sağlardım.

- K-6: Bilgisayar odamız var ama bilgisayarlar çok eski. Öğrencilerimin bilgisayar seviyesi çok düşük ve kendimi de tam anlamıyla bu konuda yeterli görmüyorum.

Katılımcıların vermiş olduğu yanıtlar incelendiğinde, katılımcılar bilgisayar laboratuvarlarını daha çok görsel sunum amaçlı kullanacakları ayrıca katılımcıların bilgisayar laboratuvarlarında ders işleme hususunda mesleki yönden yetersiz oldukları ve öğrencilerin bu konu hakkında yeterli hazırbulunuşluğa sahip olmadıkları görülmektedir. Hizmetiçi eğitim temasında olduğu gibi burada da öğretmenlerin öğretim teknoloji ve materyalleri ko- 
nusundaki beceri eksikleri teknolojinin entegrasyonu konusunda görselleştirme algısı altında yatan bir dinamik olduğunu söylemek yerinde olacaktır.

Öğretmenlerin mesleki yönden kendilerini yetersiz olarak algılaması hususunu açılamak adına kendilerinin hazırladığı ya da temin ettiği öğretim teknolojileri ve materyallerinin neler olduğu ile ders işleme sürecinde öğrencilerin öğretim teknolojilerini aktif olarak kullanabilecekleri ortamları düzenleyip düzenlemediklerine dair görüşlerine başvurulmuştur.

Tablo 7. Mesleki yeterliliğe ilişkin tema ve kodlar

\begin{tabular}{ll}
\hline Tema & Kodlar \\
\hline Mesleki Yeterlilik & Sunum hazırlama, Hazırdakileri kullanma, Var olanla yetinme \\
\hline
\end{tabular}

Tablo 7'e bakıldığında, Mesleki Yeterlilik teması kapsamında 3 ayrı kodun olduğunu görülmektedir. Kodların ulaşılmasını sağlayan katılımcılardan bazılarının yanıtları aşağıda verilmiştir.

\section{Mesleki Yeterlilik}

- E-1:Oyun hamurlarm dışardan temin edip günün konusuyla ilgili şekiller yaptırıyorum. Öğrencileri aktif kılabilmek adına sını içinde sadece akıllı tahtayı kullaniyoruz.

- E-2: Kendi hazırladığım ya da temin ettiğim bir öğretim materyali yok. Harita, küre ve akıll tahtalar öğrencilerin görebilecekleri şekilde sinıfi düzenliyorum.

- E-4: Evet. Özellikle MEB, bazı internet sitelerine sinırlama getirdiği için bazı sitelerden bazı etkinlikleri indirerek derslerde kullaniyorum. EBA portalı üzerinden kuruduğum gruplarla öğrencilerin bu teknoloji aktif olarak faydalanmasını sağlıyorum.

- E-5: Dizüstü bilgisayarmm getiriyorum. Konular bazen slaytlarla özetliyorum. Evet. Akıllı tahta üzerinden etkinlik olsun soru çözümü olsun bunlar yapabilmek adına böyle bir düzenleme yapıyorum.

- K-1: Oyun kartlarmm, kendi haritalarn getiriyorum. Aktif olarak ise haritalar sinufta burakarak merak ettikleri yerleri görmesini sağlnyorum.

- K-6: Kendi evimde araştırdığım sunular, slayt gösterilerini temin ediyorum. Bunlarn daha sonra flash disklerime atarak akill tahtalar yardimiyla simifta sunuyorum. Evet özellikle akıllı tahta üzerinden test sorusu çözerken kendilerini kaldırıp cevaplarm akıll tahta üzerinden dokunarak cevap vermelerini sağladım. Buradaki amacım öğrencinin ilgisini çekmek ve konuya katılımlarım sağlamaktı. 
Katılımcıların cevapları incelendiğinde, katılımcıların geniş ağ bağlantısı ile hazır gösterim programların indirdiklerini, günün konusuna uygun şekiller elde edebilmek adına oyun hamurları kullandıklarını ve sınıf ortamında var olan öğretim materyallerinden yararlandıkları görülmektedir. Açıklamadan hareketle, öğretmenlerin materyal geliştirme ve öğretim teknolojilerini kullanma ve kullandırma konusundaki mesleki yeterliliklerinin alt düzeyde olduğu şeklinde yorumlanabilir. Bu bulgu aynı zamanda Hizmetiçi Eğitim ile Bilgisayar Laboratuvarl Ders temasından elde edilen bulgularıyla paralel olup katılımcların mesleki yetersizliklerinin görselleştirme algısına sahip olmasında etkili olduğu söylenebilir. Katılımcıların görselleştirme algısı üzerindeki bir başka dinamik ise Tablo 8'de verilmiştir.

Tablo 8. Eğitime teknoloji entegrasyonuna adına okul imkânlarn yönelik tema ve kodlar

\begin{tabular}{ll}
\hline Tema & Kodlar \\
\hline Okul İmkânları & Yeterli, Yetersiz, Orta düzey \\
\hline
\end{tabular}

Tablo 8'de üç farklı koddan oluşan tek bir temanın olduğu görülmektedir. Ulaşılan bu temaya açılık getirebilmek adına katılımcılardan bazılarının görüşleri aşağıda verilmiştir.

\section{Okul İmkânları}

- E-1: Kırsal kesimde taşıma merkezli bir okul olduğu içim yeterli maddi imkânı yok okulun. Devlet eliyle teknolojinin temini yapılıyor. Bunun dışında okulun özel çabastyla temin ettiği teknolojik bir alet ya da materyalimiz yok. Genelde haritalar küreler oluyor sağlama konusunda. Bunlarm dışında akıllı tahtalarımı yerleştirildi. Bununla birlikte daha önce bilgisayar sinıfları ve projeksiyonlar vardl. Fatih projesi ile birlikte bunlar önemini yitirdi.

- E-2: Yeterli düzeyde buluyorum. Okulumuz eğitim teknolojileri açısından orta düzeyde. Orta düzeye koymamın nedeni Sosyal bilgiler dersliğinin olmaması... Bunun dışında akıllı tahtalarmı var bu yüzden de... Okulumuz bize harita, küre ve akıllı tahta gibi imkânları sunuyor. Bunlardan yararlanarak derslerimde ögrencilerin görerek konuların anlatımını să̆lıyorum.

- E-3: Internet bağlantısindan akull tahtasina kadar bence okulumuzdaki teknoloji yeterli bence... ilçedeki internet kesintileri ve akıll tahtalardaki teknik sorunlar yüzünden okulumuz orta seviyede... Okulumuz teknolojik olarak bir şey sağlamiyor. Harita ve kürelerin bulunduğu odalar var oraya kullanabili- 
yoruz. Fatih projesi ile birlikte bunların da kullanım azald. EBA programı içinde her türlü harita mevcut... Sinflardaki akıll tahtalar bana yetti.

- E-5: Türkiye standartlarnda yeterli buluyorum. Okulumuz... evet akull tahta kullanımın konusunda să̆lıyor. Konu tekrar ve EBA testleri çözmekte kullanyorum.

- K-2: Köy okulu olmasına rağmen elimizin altında her şey var. Harita, akull tahta vs. internetimiz de var... . Köy okulu olmasina rağmen orta seviyedeyiz. Okulumuz yeterince harita să̆llyor. Bu dersin ana unsuru bu bence... okulumuz bize sağlıyor bir sıkıntımız yok.

- K-5: akıllı tahtalarımız olduğu için aslında teknoloji rahat kullanabiliyoruz. Okulumuzun imkanları orta derece derim... Tabii... akıllı tahtalardan ziyade küre, haritalarmızı sağlıyor. Müdür Bey'e eksiğimiz var dediğimizde araştırıyor. Haritalar ile örneğin Kütahya ilimizin şurda deyip öğrencilere gösterebiliyoruz...

- K-6: Okulumuz köy okulu olduğu için telefonlarmız bile zar zor çekiyor. Internet hatları çok zayıf akıll tahtalarmmzı bile zar zor kullanıyoruz. Okulumuz alt seviyede... Okumuz akıll tahta, harita küre temini sağlıyor fakat dediğim gibi akull tahtalardan tam verim alamyorum.

- K-8: Evet. Imkânlarımız müsait. Her sinıfta akıllı tahtalarımız var. Her türlü imkanı să̆lıyorlar. Akıllı tahtalarımız arızalandı̆̆ında onarımı yapılıyor.

Tablo 1'de belirtildiği üzere, çalışma grubunda 7 köy okulu, 3 ilçe merkez okulu ve 5 il merkez okulu öğretmeni yer almıştır. Yine bu öğretmenlerden 3'ü okullarını sosyo-ekonomik düzey açısından alt seviyede, 7'si orta seviyede ve 5'i de üst seviyede değerlendirmiştir. Katılımcıların vermiş olduğu cevaplardan hareketle, okullarında geniş ağ bağlantılı akıllı tahtaları tam verimli şekilde kullananlar okullarını yeterli, verim alamayanlar ise alt seviyede değerlendirmiştir. Akıllı tahtalarda ufak sorunlar yaşayanlar ise okullarını teknolojik donanım açısından orta seviyeye yerleştirmişlerdir. Bunun yanında akıllı tahtaların sınıf ortamına girmesiyle birlikte görsel yönden somutluk sağlayan diğer teknolojik araç ve öğretim materyallerinin atıl duruma düştüğü ayrıca bu akıllı tahtaların öğretmen merkezli bir anlayışta kullanıldığı ve görsellik işlevini yerine getirdiği görülmektedir. Tüm bu açıklamalardan hareketle, katılımcılar okullarının teknolojik imkânlarını akıllı tahtaların kullanım elverişliliği kriterine göre değerlendirdikleri ayrıca okulların sahip olduğu bu imkanların katılımcıların eğitme teknoloji enteg- 
rasyonu algılarının görselleştirme boyutunda olduğu söylenebilir. Okulların teknolojik imkanları katılımcıların görselleştirme algılarında bir etken olduğu lakin okulların teknolojik yönden üst ya da alt seviyede olması katılımc1ların algılarında bir farklılık yaratmadığını söylemek yerinde olacaktır.

\section{Tartışma, Sonuç ve Öneriler}

Araştırmada; Görselleştirme, Hizmetiçi Ĕ̆itim, Eğitime Teknoloji Entegrasyonu, Okul İmkânları, Ulaşabilirlik, Bilgisayar Laboratuvarh Ders ve Mesleki Yeterlilik olmak üzere 7 farklı tema elde edilmiştir. Bu temaların içeriklerinden hareketle, araştırmaya katılan sosyal bilgiler öğretmenlerinin eğitime teknoloji entegrasyonu algılarının görselleştirme boyutunda olduğu sonucuna varılmıştır. Öğretmenlerin görselleştirme algısı altında yatan dinamikleri ise öğretmenlerin mesleki yetersizlikleri, okulların teknolojik yönden donanımları, öğretim teknoloji ve materyalleri hususunda öğretmenlere sunulan hizmet öncesi ve hizmetiçi eğitimlerin yetersizlikleri oluşturmuştur. Ayrıca araştırmaya katılan sosyal bilgiler öğretmenlerinin öğretim teknoloji ve materyalleri öğreten merkezli bir yapıda sunum amaçlı kullandıklarından dolayı araştırmaya katılan öğretmenlerin teknolojinin entegrasyonu konusunda Tip I boyutunda olduğu sonucuna varılmıştır. Öğrencinin ve öğretmenin teknoloji kullanması konusunda, Tip I kullanımı geleneksel yollarla öğrenciye bilgi aktarım sürecini ifade ederken, Tip II kullanımı ise öğrencinin aktif olduğu, teknoloji/materyalin öğrenci tarafından bizzat kullanıldığı ya da tasarlandığı süreci savunan görüştür (Maddux ve Johnson, 2006). Bir teknolojinin sınıflarda çok sık kullanılıyor olması veya öğretimin odağında teknolojinin kendisinin olması entegrasyonun tam olarak gerçekleştiği anlamına gelmemelidir (Stephens, 2011). Bu açiklamalardan hareketle, sosyal bilgiler dersinde teknolojinin entegrasyonu söz konusu olmayı teknolojinin kullanımı söz konusudur. Varılan bu sonucun aynı zamanda Şanl, Sezer ve P1nar (2016)'daki coğrafya öğretmenlerinin, coğrafya öğretimde teknoloji entegrasyon algıları ve uygulamalarını ortaya koymak amacıyla yürüttüğü çalışmasının sonuçlarıyla benzer olduğu görülmüş̧ür.

Araştırma bulgularından hareketle, araştırmaya katılan öğretmenlerin etkileşimli tahtaların eğitim ortamında kullanılmasıyla ilgili hizmetiçi eğitimlere katıldığı lakin bu eğitimin teknolojinin eğitim ortamına entegrasyonu açısından yetersiz olduğu görülmüştür. Kefeli (2013) “Öğretim Sürecinde 
Etkileşimli Tahta Kullanımına Yönelik Geliştirilen Bir Hizmet İçi Eğitim Kursu ve Yansımaları" konulu çalışmasında, çalışmaya katılan öğretmenlere uygulanan hizmetiçi eğitimin izleme ve değerlendirme çalışmaları sonucunda hizmetiçi eğitimlerinin uygulanabilir olduğu ama etkili teknoloji entegrasyonu için tek başına yeterli olmadığı; kurs sonrasında sağlanacak destek hizmetlerinin de önemli olduğundan bahsedilmiştir. Bu bağlamda, etkileşimli tahtalarla ilgili hizmetiçi eğitimlerin teknolojinin eğitim ortamına entegrasyonu açısından tek başına yeterli olmadıklarını söyleyebiliriz. Arslan (2016)'daki çalışmasında da öğretmenlere sınıf içinde teknolojinin kullanılması ile ilgili hizmetiçi ve hizmet sonrası eğitimlerin teknolojinin entegrasyonu açısından yetersiz olduğu görülmüştür.

Araştırmaya katılan öğretmenlerin teknoloji kullanma ve öğretim materyali tasarlaması açısından yaratıcı fikir ve becerilerinin yetersiz olduğunu sonucuna varılmıştır. Sezer, İnel ve Gökalp (2019) tarafından çalışma grubunu Sosyal Bilgiler öğretmenlerinin oluşturduğu Türkiye deki lisansüstü tezlerini mercek altına aldığı çalışmada da sosyal bilgiler öğretmenlerinin teknoloji bilgilerinin yetersiz ve teknolojinin eğitime entegrasyonu açısından eksik yine bu yöndeki algılarının da yetersiz olduğu tespit edilmiştir. Sosyal bilgiler öğretmenlerinin teknolojiyi kullanma konusundaki yetersizlikleri sonucuna paralel olarak Sarı ve Altun (2015) tarafından çalışmada da sınıf öğretmenlerinin teknolojiyi kullanma konusunda zorluklar yaşadığı görülmüştür. Çakır ve Yıldırım (2009) öğretmen yetersizliğini teknolojinin entegrasyonunu etkileyen bir unsur olduğundan bahsetmiştir. Bu sonuçlar 1ş1ğında, öğretmenin teknoloji kullanama yetersizliği eğitimde teknolojinin entegrasyonu etkilediği şeklinde değerlendirilebilir. Ayrıca araştırmaya katılan sosyal bilgiler öğretmenlerinin teknoloji entegrasyonunu sadece sinıf içi bir etkinlik olarak düşünmesi erişilen bir başka sonuçtur.

\section{Öneriler}

$\checkmark \quad$ Sosyal bilgiler öğretmenlerin kendilerini gelişen teknolojik gelişmeler karşısında yenileyebilmelerini sağlamalıdır.

$\checkmark \quad$ Üniversitelerde öğretim teknoloji ve materyal geliştirme programları gözden geçirilmeli, bilgilerin kalıcılığı adına uygulama programlarına ağırlık verilmelidir. 
$\checkmark \quad$ Sosyal bilgiler öğretmenlerine öğretim ve uygulamalarında teknolojinin entegrasyonu kapsamında uygulamalı hizmetiçi eğitimi verilmeli ve bu hizmetiçi eğitimlerin belli periyotlara takibi yapılarak, verilen uygulamalı eğitimlere yönelik yapıcı dönütler sağlanmalıdır.

$\checkmark$ Okulların fiziki alt yapıları iyileştirilip sosyal bilgiler öğretmenlerinin, sınıf içi ve sınıf dışı faaliyetlerinde teknolojinin entegrasyonunu sağlayabilecek firsatlar sunulmalıdır. 


\title{
EXTENDED ABSTRACT
}

\section{Social Studies Teachers' Perceptions on Technology Integration in Education}

\author{
Ali Gökalp - Adem Sezer - Yusuf İnel \\ Uşak Üniversitesi
}

The concept of educational technology has emerged as a result of technology starting to be used in educational institutions. Educational technology is defined as the functional structuring of learning or teaching that processes by employing knowledge and skills, and the design, implementation, evaluation and development of teaching-learning processes so as to dominate education in general, and learning in particular. Apart from technology, the developments in the area of intelligence have also allowed to prepare programs that appreciate the individual differences of the students. With these programs, the relationship between education and technology has further strengthened, and stimulation of more sensory organs in this educational environment has made it possible to achieve meaningful and permanent learning. The elements of educational technology have a hierarchical order, and learning by doingexperiencing has occupied the highest place in this order.

In order to enrich learning environments and to involve the student in the learning process, studies regarding the use of technology in education and to integrate technology with education have started to be carried out. However, using technology and integrating technology are totally different concepts, and thus, using technology in classes does not necessarily mean it integration with education. Also, the frequent use of any technology in classes, or technology itself being the focus of education does not mean that integration has been thoroughly achieved. There are two different views regarding the use of technology by the students and the teacher, which are Type I use and Type II use. While Type I use refers to the transfer of knowledge to the student in conventional ways, the view regarding Type II use advocates the process in which the stu- 
dent is active, and technology/material is used and designed by the student himself/herself.

The aim of the study was to determine the perceptions of social studies teachers regarding the integration of technology into education. The study was designed as a phenomenological study in accordance with qualitative research method. In the study, as it was aimed to reveal the perceptions of social studies teachers about the integration of technology in their teaching and applications through their own experiences, phenomenology was preferred.

The study group consisted of 15 social studies teachers working in 12 different secondary schools affiliated with the Ministry of National Education in Uşak province in the fall semester of the 2017-2018 academic year. Of the 15 teachers, 8 were female, and 7 were male. Female teachers were coded as $\mathrm{K}-1, \mathrm{~K}-2, \mathrm{~K}-3, \ldots$, and male teachers as E-1, E-2, E-3, ...; thus, their privacy was protected. In order to collect the data of the study, a semi-structured questionnaire was prepared by the researchers. Then, the questions were asked to the teachers through face-to-face interviews. Prior to the interviews, the consent of the participants was obtained, and after the data obtained were stored in a smartphone, they were transcribed for the analysis. The data obtained were analyzed with descriptive analysis method. Descriptive analysis is an analysis method where the data are shown, depicted and analyzed as they are. That is, there is no detailed and theoretical analysis. It is known that the questions asked by the researcher are expressed with a concept or a statement, and these must be of a nature that is compatible with and covering the responses of the participants. Accordingly, the participants' responses were coded by three different coders. Later, the themes were reached from the codes obtained. All these processes were illustrated in tables, and they were interpreted with sample quotations.

In the study, 7 different themes were obtained as Visualization, Inservice Training, Integration of Technology into Education, School's Resources, Accessibility, Lesson Supported with Computer Laboratory, and Professional Competence. Based on the contents of the themes, it was concluded that the perceptions of participating social studies teachers regarding the integration of technology into education was at the visualization dimension. The dynamics underlying the teachers' visualization perceptions 
were comprised of the teachers' professional incompetence, the schools' technological equipment, and the insufficiency of pre-service and inservice training provided to teachers on educational technologies and materials. In addition, since the social studies teachers participating in the study used educational technologies and materials for presenting purposes with a teacher-centered approach, it was concluded that the participating teachers fell in the Type I category in terms of the integration of technology. While Type I use refers to the transfer of knowledge to the student in traditional methods, the view regarding Type II use advocates the process in which the student is active, and technology/material is used and designed by the student himself/herself. The frequent use of any technology in classes, or technology itself being at the very center of education should not mean that integration has been thoroughly achieved. In the light of these explanations, it can be stated that the use of technology rather than the integration of technology is available in the social studies course.

Other results obtained in the study are as follows: It was found that the teachers participating in the study took part in in-service training programs on the use of interactive boards in educational environments, but that this training was not sufficient in terms of the integration of technology into education and was lacking in terms of providing the teachers with creativity and skills to use the technology and design teaching materials. Another finding was that the social studies teachers participating in the study considered the integration of technology only as an in-class activity.

The results obtained were discussed along with the studies conducted in the relevant literature. Then, some suggestions were made. These suggestions are:

$\checkmark \quad$ It should be ensured that social studies teachers should adapt themselves to the developing technology.

$\checkmark$ Educational technologies and material development courses in the universities should be revised, and application programs should be emphasized in order to ensure permanent learning.

$\checkmark$ Applied in-service training should be provided to social studies teachers within the scope of the integration of technology in education and applications, and these in-service training programs should 
be followed up regularly and constructive feedback should be obtained regarding applied trainings provided.

$\checkmark$ The physical infrastructure of the schools should be improved, and social studies teachers should be given opportunities that would ensure the integration of technology in in-class and out-of-class activities.

\section{Kaynakça / References}

Alkan, C. (1996). Eğitim teknolojisi. Ankara: Atilla Kitabevi.

Arslan, S. (2016). Eğitimde teknoloji entegrasyonunu etkileyen faktörlerdeki değişimlerin incelenmesi. Yayımlanmamış yüksek lisans tezi. Ondokuz Mayıs Üniversitesi, Samsun.

Creswell, J.W. (2007). Qualitative inquiry and reserach design: Choosing among five approaches. (2nd Press). Sage Publications.

Çakır, R. ve Yıldırım, S. (2009). Bilgisayar öğretmenleri okullardaki teknoloji entegrasyonu hakkında ne düşünürler? Elementary Education Online. 8(3), 952-964.

Çoklar, A. N., Kılıçer, K., ve Odabaşı, H. F. (2007). Eğitimde teknoloji kullanımma eleştirel bir bakış: Teknopedagoji. The proceedings of 7th InternationalTechnology Conference, 3-5 May 2007, Near East University, North Cyprus.

Çelik, E. (2007). Ortaöğretim coğrafya derslerinde bilgisayar destekli animasyon kullanmminn Öğrenci başarısına etkisi. Yayınlanmamış yüksek lisans tezi. Marmara Üniversitesi, İstanbul.

Çilenti, K. (1988). Eğitim teknolojisi ve öğretim. Ankara: Kadıŏlu Matbaası.

Demir, S., Özmantar, F. M., Bingölbali, E. ve Bozkurt, A. (2011). Sınff öğretmenlerinin teknoloji kullanmalarmnn irdelenmesi. 5th International Computer $\mathcal{E}$ Instructional Technologies Symposium, 22-24 September 2011 Furat University, Elazı ̆.

Demircioğlu, H. G. (2000). Eğitimde yeni hedefler ve çoklu zekâ yaklaşımı. Çocuk Gelişimi ve Eğitimi Dergisi. 1(2), 47-50.

Gardner, H. (1993). Multiple intelligences: The theory in practice, New York: Basic Book.

Holznogel, D. (2005). Is technology integration happening? How can i tell? NETC Circuit. http://www.netc.org/circuit/2005/winter/tech.html adresinden erişilmiştir.

Kefeli, P. (2013). Öğretim Sürecinde Etkileşimli Tahta Kullanmmma Yönelik Geliştirilen Bir Hizmet İ̧i Ĕ̆itim Kursu ve Yansımalan. Yayımlanmamış Yüksek Lisans Tezi. Karadeniz Teknik Üniversitesi, Trabzon.

Koehler, M. J. ve Mishra, P. (2005). Teachers learning technology by design. Journal of Computing in Teacher Education. 21(3), 94-102. 
Maddux, C. D. ve Johson, D. L. (Eds.) (2006). Type II uses of technology in teaching: Projects, case studies and soft applications. New York: Haworth Press.

Matheison, B. (2011). Learning v. understanding: The difference between technology use and technology integration in the elementary classroom. http://sites.google.com/site/brittanymatheison/lessonplans adresinden 12.12.2018 tarihinde erişilmiştir.

Punch, K. F. (2005). Sosyal araştırmalara giriş: nicel ve nitel yaklaşımlar. (D. Bayrak, H.B. Arslan, Z. Akyüz, Çev.) Ankara: Siyasal Kitapevi.

Sarı, M.H. ve Altun, S.A. (2015). Sınıf öğretmenlerinin matematik öğretiminde teknoloji kullanımı üzerine nitel bir çalışma. International Journal Of Eurasia Social Sciences, 6(9), 24-49.

Sezer, A., İnel, Y. ve Gökalp, A. (2019). Çalışma grubu sosyal bilgiler öğretmenleri olan Türkiye'deki lisansüstü tezlerin incelenmesi. Uşak Üniversitesi Sosyal Bilimler Dergisi (Aralık 2019 sayısına kabul edildi).

Sönmez, V. ve Alacapınar, F.G. (2014). Örneklendirilmiş bilimsel araştırma yöntemleri. Ankara: Anı Yayıncilı.

Stephens, M. (2011). Technology integration through teacher training. http://marquea2.wordpress.com/2008/09/04/final-revision-of-arp/ adresinden 13.12.2018 tarihinde erişilmiştir.

Şanl, C., Sezer, A. ve Pınar, A. (2016). Perceptions of geography teachers to integrating technology to teaching and their practices. RIGEO, 6(3), 234-252.

\section{Kaynakça Bilgisi / Citation Information}

Sezer, A., İnel, Y. ve Gökalp, A. (2020). Sosyal Bilgiler öğretmenlerinin öğretim ve uygulamalarında teknolojinin entegre edilmesine yönelik algıları. OPUS-Uluslararası Toplum Araştırmaları Dergisi, 16(Eğitim ve Toplum Özel Sayıs1), 5626-5650. DOI: 10.26466/opus.660674 